\title{
Historical perspectives of The American Association for Thoracic Surgery: Michael E. DeBakey (1908-2008)
}

Daniel Eads, MD, and John S. Ikonomidis, MD, PhD

Michael Ellis DeBakey, 38th president of The American Association for Thoracic Surgery (AATS), was born in Lake Charles, Louisiana, on September 7, 1908, to parents who had emigrated from Lebanon. His father was a pharmacist who ran 2 pharmacies, where DeBakey first encountered many physicians who inspired him to go into the field of medicine. He credited his mother for teaching him to sew from a young age. His parents insisted he and his siblings read a new book from the library every week. DeBakey recalls, "I was around seven when I found the best book I'd ever seen in the library. When I asked to take it home, the librarian refused. This fascinating book... The Encyclopedia Britannica." ${ }^{11}$ In addition to instilling the values of education and self-discipline, DeBakey also credited his parents for instilling their children with compassion; every Sunday, his family would deliver clothes and warm cooked meals to a local orphanage. ${ }^{1}$

\section{EDUCATION AND SURGICAL TRAINING}

He was valedictorian of his high school class and attended Tulane University in New Orleans for his undergraduate studies. Before starting at Tulane, DeBakey mastered the saxophone, which allowed him to join Tulane's band; however, DeBakey purchased a clarinet. In a few short months he learned to play the clarinet, and his dedication quickly earned him a position in the Tulane orchestra clarinet section. Dr DeBakey often mentioned that playing musical instruments taught him both dedication and manual dexterity, both of which he considered necessary qualities for a surgeon. ${ }^{2}$ After completing 2 years of undergraduate study, he was accepted to Tulane Medical School. He felt compelled to complete his undergraduate studies; therefore, he convinced his professors to allow him to complete his final 2 years of undergraduate education and obtained his bachelor's degree during his first 2 years of medical school. During the latter 2 years of his medical education, he encountered 2 mentors-Drs Rudolph Matas (third AATS president) and Alton Ochsner (27th AATS president) -

\footnotetext{
From the Division of Cardiothoracic Surgery, Medical University of South Carolina, Charleston, SC.

Disclosures: Authors have nothing to disclose with regard to commercial support.

Received for publication Dec 9, 2013; accepted for publication Dec 17, 2013; available ahead of print Feb 16, 2014.

Address for reprints: John S. Ikonomidis, MD, PhD, Division of Cardiothoracic Surgery, Medical University of South Carolina, 25 Courtenay Dr, Suite 7030,

Charleston, SC 29425 (E-mail: ikonomij@musc.edu).

J Thorac Cardiovasc Surg 2014;147:1123-7

$0022-5223 / \$ 36.00$

Copyright (c) 2014 by The American Association for Thoracic Surgery http://dx.doi.org/10.1016/j.jtcvs.2013.12.029
}

both of whom he acknowledged played an important role in his development as a future surgeon. DeBakey, who had mastered the ability to read both French and German before entering medical school, began translating French and German medical articles for his professors at Tulane. Many of these articles were provided from Dr Matas' personal foreign journal library. Dr Matas was so impressed with DeBakey that they continued to have a professional and personal relationship for many years after their first encounter. ${ }^{3}$ DeBakey began working in Dr Ochsner's laboratory in his last year of medical school; Dr Ochsner convinced Dr DeBakey to go into the field of surgery and complete both his surgical internship and residency at Tulane. ${ }^{3}$ After completing his surgical residency, he completed 2 years of surgical fellowship in Europe under the direction of Dr Rene Leriche at the University of Strasbourg and Dr Martin Kirschner at the University of Heidelberg.

\section{SURGICAL CAREER}

After completing 2 years of surgical fellowship abroad, he was accepted on the surgery faculty at Tulane Medical School in 1937. In 1942, he volunteered for the Army Medical Corps and was assigned to the Surgical Consultants' Division in the Office of the Surgeon General in Washington DC. In this role, he inspected field hospitals and performed surgery in Europe. His experience there led to recommendations for improved surgical management of wounded soldiers and, eventually, to the development of the mobile army surgical hospitals also known as MASH units. ${ }^{4} \mathrm{He}$ rose to the rank of colonel and received the Legion of Merit Award in 1945 for his contributions during the war. At the completion of the war, he recognized the need for specialized care for returning veterans in multiple geographic locations across the United States. His contributions and recommendations ultimately led to the development of the Veteran's Administration Medical Center Hospital System and Research System. ${ }^{4}$ In an interview in 1998, Dr DeBakey also highlighted one of his greatest accomplishments initiated during his time in the Army Medical Corps: the conversion of the Surgeon's General Library to the National Library of Medicine, which is under the direction of the National Institutes of Health.

After completing his service in the Army, Dr DeBakey returned to the faculty at Tulane for a short period before being recruited to Baylor in 1948 as the chair of the department of surgery. Dr DeBakey was initially underwhelmed by the offer to chair the surgery department at Baylor and 
actually turned the position down twice before accepting the position. At his arrival, he noted that "Baylor University College of Medicine had no teaching hospital, no [surgical] service, and no [National Institutes of Health] $\mathrm{NIH}$ grants." ${ }^{3}$ He quickly went to work and developed affiliations with the local Veterans Affairs and county hospitals. In 1968, he was appointed dean of the medical college and promptly separated the medical school from Baylor University, obtaining an independent charter from Texas for the Baylor College of Medicine. He served as president of the college of medicine from 1969 to 1979, chancellor from 1979 to 1996, and remained chair of the surgery department until 1993.

\section{ACCOMPLISHMENTS AND CONTRIBUTIONS TO THE FIELD OF CARDIOTHORACIC SURGERY}

During his lengthy career, DeBakey made countless contributions to the field of medicine and surgery. One of his earliest contributions came while he was still a medical student at Tulane University when he developed the concept of the roller pump (Figure 1). He initially used the roller pump for blood transfusions, drawing blood directly from a donor and transfusing into the recipient. In his early years on the faculty at Tulane, he and Dr Ochsner together documented the rapid increase in primary pulmonary carcinoma in the early decades of the 20th century. Additionally, they published multiple reports on the options available for the surgical management of lung cancer and suggesting the correlation between tobacco smoking and primary pulmonary carcinoma. ${ }^{5-7}$

Dr DeBakey made some of his greatest contributions to the field of cardiovascular surgery related to the surgical management of aortic aneurysms. He performed the first abdominal aortic aneurysm repair in the United States in 1952, only months after Dr Charles Dubost completed the first ever procedure in Paris. ${ }^{3}$ His first aneurysm repairs were completed with aortic homografts that DeBakey had harvested himself. He applied this similar knowledge and experience to perform the first thoracic aortic aneurysm repair in $1953 .{ }^{8}$ Ever in pursuit of surgical advancement, Dr DeBakey sought an alternative to homografts for conduits in his repair of aortic aneurysms. His original plan was to develop a conduit made of nylon; however, when he went to his local department store to find nylon material from which to create his conduit, they did not have any in stock. The clerk suggested instead a new material called "Dacron," which Dr DeBakey used to create his first artificial grafts and is still the primary material used in aortic grafts today. Dr DeBakey initially created and sewed all his own Dacron grafts and even produced them for his colleagues until they became commercially available in the late $1950 \mathrm{~s}^{3}$ (Figure 2).

In 1953, Dr DeBakey performed the first documented carotid endarterectomy on a patient who had reported symptoms of cerebrovascular insufficiency. He published

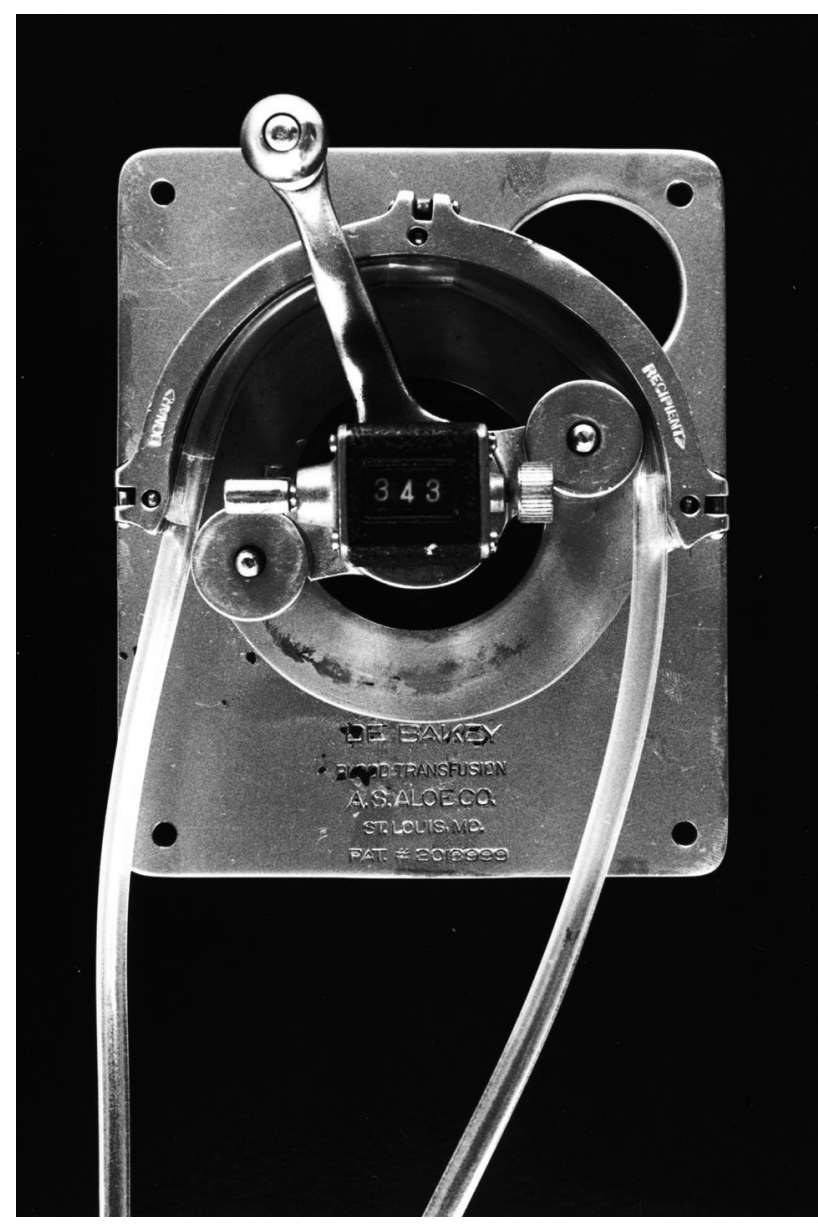

FIGURE 1. Dr DeBakey's roller pump (courtesy of the Baylor College of Medicine).

his findings and 19-year follow-up data showing the patient to be without cerebrovascular symptoms and providing evidence of persistent blood flow through the carotid artery. ${ }^{9}$ DeBakey not only played a major role in development of aortic and carotid revascularization, but

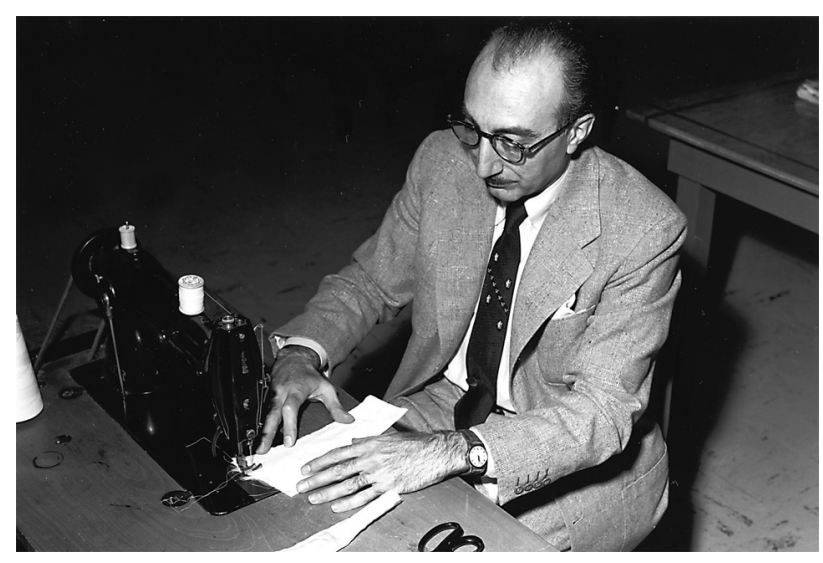

FIGURE 2. Dr DeBakey created a Dacron graft on his wife's sewing machine (courtesy of the Baylor College of Medicine). 


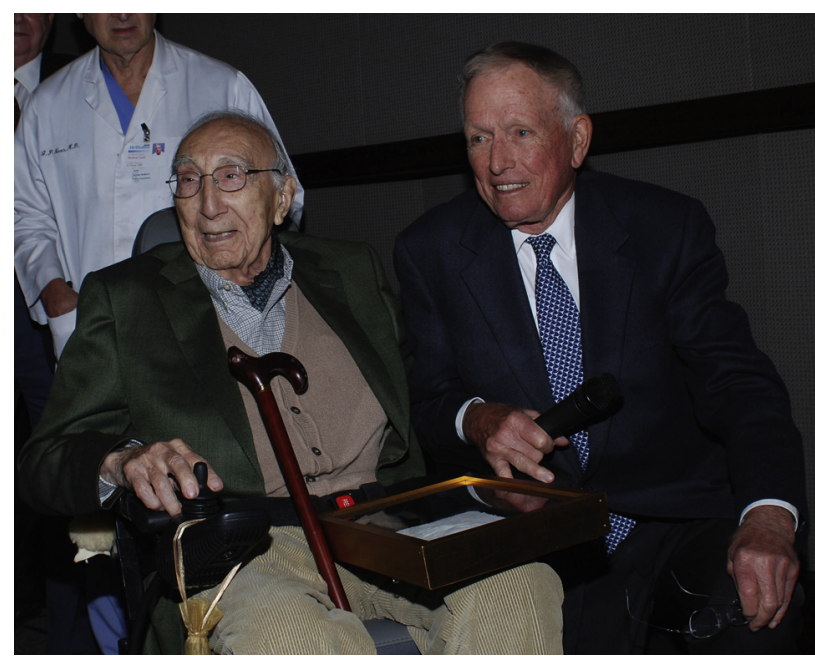

FIGURE 3. Dr DeBakey with Dr Cooley accepting his honorary membership into the Denton A. Cooley Cardiovascular Society.

also in coronary revascularization. In the early 1960 s, he published his data regarding coronary artery bypass grafting with Dacron grafts in canines. ${ }^{10}$ This was followed by his performance of the first successful case of saphenous vein coronary artery bypass grafting in 1966 after a complication occurred during a coronary artery endarterectomy. ${ }^{11}$

At a time when heart transplantation had become a popular alternative for those with advanced cardiac disease, Dr DeBakey pursued new developments in the areas of artificial hearts and ventricular assist devices (VADs). Dr DeBakey pursued both technologies as alternatives and bridges to cardiac transplantation. His initial success with VADs and disappointing laboratory results with the total artificial heart in calves led him to abandon artificial heart research in favor of the VADs. ${ }^{3,12,13}$ Denton Cooley implanted a version of the total artificial heart in a patient at Baylor that led to one of the most renowned conflicts in the history of cardiovascular surgery between Drs DeBakey and Cooley. At the time, it resulted in the resignation of Dr Cooley; however, the dispute was resolved 4 decades later when Dr DeBakey was accepted into the Denton A. Cooley Cardiovascular Society $^{4}$ (Figure 3). Dr DeBakey's continued research and collaboration with National Aeronautics and Space Administration engineers led to the development of an axial flow pump and, eventually, to the MicroMed DeBakey $\operatorname{VAD}^{12}$ (Figure 4).

DeBakey considered one of his greatest contributions to the field of surgery to be the surgeons he trained during his lengthy career. ${ }^{1}$ Many residents have acknowledged Dr DeBakey as a demanding leader with zero tolerance; he instilled 2 principles in all his trainees: "attention to detail at all times" and "pursue excellence in all things." 14

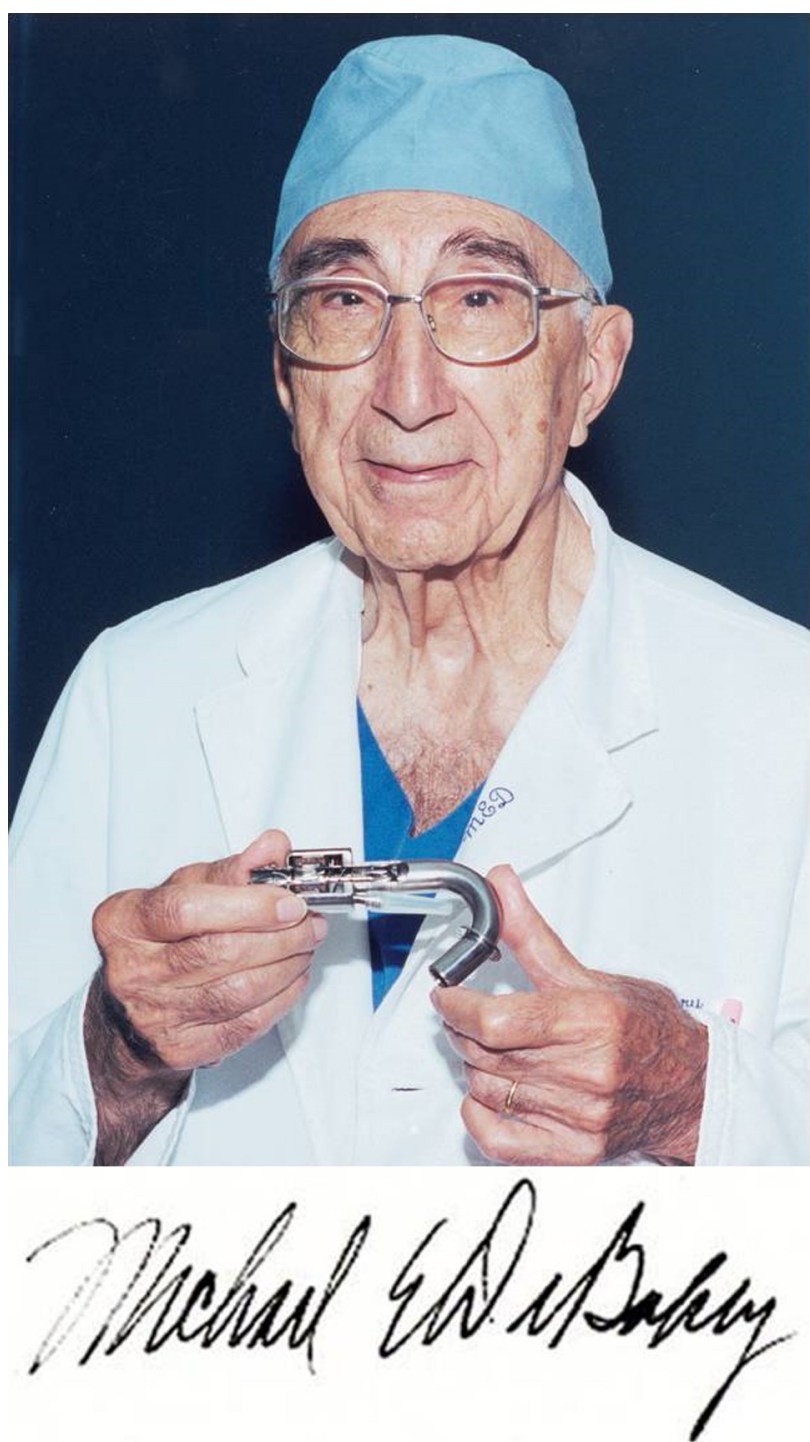

FIGURE 4. Dr DeBakey with the DeBakey ventricular assist device (courtesy of the Baylor College of Medicine), with the signature of Dr Michael E. DeBakey.

\section{CURRICULUM VITAE HIGHLIGHTS}

In addition to his many appointments, contributions, and accomplishments outlined in the preceding paragraphs, Dr DeBakey published more than 1400 medical articles and chapters and authored multiple books, including The Living Heart, The Living Heart Diet, and The New Living Heart. In addition to being awarded the Legion of Merit in 1945, he received the Presidential Medal of Freedom with Distinction, the National Medal of Science, the Albert Lasker Award for Clinical Research, the Rudolph Matas Award in Vascular Surgery, the Leriche Award, and the Congressional Gold Medal. ${ }^{2}$ During the course of his career, he operated on many world leaders, including President Lyndon Johnson, President John F. Kennedy, President 
Richard Nixon, the Duke of Windsor, Russian President Boris Yeltsin, the Shah of Iran, King Leopold of Belgium, and King Hussein of Jordan. ${ }^{1}$ In addition to his participation and leadership of many medical associations, he served on the Medical Advisory Committee of the Hoover Commission; the President's Commission of Heart Disease, Cancer, and Stroke during the Johnson Administration; 3 terms on the National Heart, Lung, and Blood Advisory Council of the National Institutes of Health; and 2 terms as chairman of the Board of Regents of the National Library of Medicine. He has multiple institutes bearing his name, including the Michael E. DeBakey Veterans Affairs Medical Center in Houston, Methodist DeBakey Heart \& Vascular Center, and DeBakey High School for Health Professions in Houston, Texas, and Doha, Qatar. ${ }^{15}$

\section{SUMMARY OF AATS PRESIDENTIAL ADDRESS}

Dr DeBakey presented his AATS Presidential Address at the 38th Annual Meeting in Los Angeles in 1959. During this address, he discussed his growing experience with the surgical management of aneurysmal thoracic aortic disease specifically related to the necessity for the temporary arrest of circulation through the aortic segment to be resected. He cited 2 major hazards associated with this procedure: increased vascular resistance resulting in left ventricular strain and ischemic damage to the tissue distal to the operative site, notably the central nervous system and kidneys.

To address these 2 concerns, Dr DeBakey discussed aneurysmal disease relative to the portion of aorta involved. For those aneurysms limited to the descending thoracic aorta, DeBakey related his experience with pump bypass from the left atrial appendage to a cannula in the femoral artery that provided perfusion distal to the occluding clamps. Although he noted that this method helped prevent left ventricular strain and improved renal protection, it was not completely effective in preventing spinal cord damage. ${ }^{16}$

For aneurysms confined to the aortic arch, he used temporary bypass grafts to provide perfusion to the innominate, left common carotid, and distal aorta. He acknowledged the risk of narrowing the innominate or carotid artery in performing the end-to-side anastomosis of a bypass graft using the partial occlusion technique and noted that he overcame this risk using a temporary internal shunt when performing the end-to-side anastomosis. ${ }^{16}$ For aneurysms involving the proximal aorta, DeBakey noted the necessity of cardiopulmonary bypass. Although he acknowledged the benefits of the artificial heart-lung machine, he also noted that it provided many challenges that had yet to be satisfactorily resolved at the time of his address, including the interruption of, or decreased, coronary blood flow and the control of hemorrhage owing the necessity of heparinization. ${ }^{16}$
DeBakey noted that these procedures helped minimize the extent of operative trauma, duration of anesthesia, and amount of blood loss; however, he added that a patient's ability to tolerate such a procedure was largely determined by risk stratification. On a review of his outcomes, Dr DeBakey noted advancing age, hypertension, and associated heart disease had an important bearing on the risk of the operation. He believed the continued improvement in surgical care would allow for better outcomes and an additional reduction in surgical risk. He closed his address noting that the success or failure of the operation also relied on the surgeon's "capability, extent of clinical experience, close attention to details, preciseness and dexterity in technical performance, and perhaps the attitude and temperament of the surgeon." 16 Although the surgical outcomes might be partially determined by patient risk stratification, he clearly placed a burden on surgeons to constantly refine their technical skill and clinical experience.

\section{PERSONAL LIFE}

With all his many accomplishments and tireless dedication to his career, many considered him to be a workaholic to which DeBakey responded, "I may be considered a workaholic, but I enjoyed it. The work was part of the joy of life. And there is nothing I enjoyed more than taking care of patients." " His parents instilled these values of hard work and dedication in him from a young age, and Dr DeBakey also cared very dearly for his family and heritage. He worked closely with his siblings during the course of his career; his brother, Ernest, was a thoracic surgeon in Alabama, and his sisters, Selma and Lois, were professors at Baylor College of Medicine. ${ }^{17}$ He was married to his first wife, Diana Cooper DeBakey, until her death from myocardial infarction in 1972. He married his second wife, Katrin Fehlhaber DeBakey, in 1975. Between his 2 marriages, he had 5 children-Ernest, Barry, Michael, Denis, and Olga. In January 2006, at age 97, Dr DeBakey was hospitalized for chest pain, which, on evaluation, was found to be due to an ascending aortic dissection. After much debate, he eventually underwent surgical repair of his dissection, a surgery he had helped pioneer decades earlier. After months of recovery, DeBakey was released from the hospital in good health. ${ }^{1}$ On July 11, 2008, Dr DeBakey died of natural causes at the Methodist Hospital in Houston, Texas. He was buried in Arlington National Cemetery after being the first person ever to lay in repose in Houston's City Hall. ${ }^{18}$

\section{References}

1. Roberts W. Heart of a hero: legendary heart surgeon Michael Ellis DeBakey, M.D. recounts his extraordinary life. H Texas Magazine. 2008;27-31.

2. McCollum CH. The Distinguished Service Award Medal for the Society of Vascular Surgery, 1999: Michael Ellis DeBakey, MD. J of Vasc Surg. 2000;31: 406-9.

3. Stoney W. Pioneers of Cardiac Surgery. 1st ed. Nashville, TN: Vanderbilt University Press; 2008:148-58. 
4. Cooley D. In Memoriam Michael E. DeBakey 1908-2008. Tex Heart Inst J. 2008; 35:233-4.

5. Ochsner A, DeBakey M. Primary pulmonary malignancy: analysis of 79 collected cases and presentation of 7 personal cases. Surg Gynecol Obstet. 1939;68:435-51.

6. Ochsner A, DeCamp P, DeBakey M, Ray CJ. Bronchogenic carcinoma: it's frequency, diagnosis, and early treatment. JAMA. 1952;148:691-7.

7. Ochsner A, DeBakey M, Dixon JL. Primary cancer of the lung. JAMA. 1947;135: 321-7.

8. DeBakey M, Cooley D. Successful resection of aneurysm of thoracic aorta and replacement by graft. JAMA. 1953;152:673-6.

9. DeBakey M. Successful carotid endarterectomy for cerebrovascular insufficiency: nineteen-year follow-up. JAMA. 1975;233:1083-5.

10. DeBakey M, Henly W. Surgical treatment of angina pectoris. Circulation. 1961; 23:111-20.

11. Garret HE, Dennis EW, DeBakey ME. Aortocoronary bypass with saphenous vein graft. JAMA. 1973:223:792-4.
12. DeBakey M. Development of mechanical heart devices. Ann Thorac Surg. 2005 79:S2228-31.

13. Kennedy JH, DeBakey ME, Akers WW, Ross JN, O'Bannon W, Baker LE, et al Development of an orthoptic cardiac prosthesis. J Thorac Cardiovasc Surg. 1973 65:673-83.

14. Mattox K. Michael DeBakey: the consummate leader. Methodist DeBakey Cardiovasc J. 2009;5:32-6.

15. Gotto A. Tribute to Dr. Michael E. DeBakey. Methodist DeBakey Cardiovasc J. 2010;6:61-2.

16. DeBakey M. Presidential address: changing concepts in thoracic vascular surgery. J Thorac Cardiovasc Surg. 1959;38:145-65.

17. Salem P. Michael DeBakey: the real man behind the genius. Methodist DeBakey Cardiovasc J. 2010;6:42-4.

18. Ackerman T. Houstonians view DeBakey's casket at City Hall. Houston Chronicle July 15, 2008. Available at: http://www.chron.com/news/houston-texas/ article/Houstonians-view-DeBakey-s-casket-at-City-Hall-1591980.php. Accessed September 23, 2013 